Ann. Biol. anim. Bioch. Biophys., I975, 15 (I), 95-ror.

\title{
INFLUENCE DE LA NATURE DES PROTÉINES ALIMENTAIRES SUR L'AMINOACIDÉMIE DE L'AGNEAU PRÉRUMINANT
}

\author{
P. PATUREAU-MIRAND, M. THERIEZ* et J. PRUGNAUD
}

avec la collaboration technique de Françoise BArRé, Marie-Claude VALLuY et Gr. Bayle

\author{
Laboratoire d'Étude du Métabolisme azoté, \\ * Laboratoire de la Production ovine, \\ Centre de Recherches de Clermont-Ferrand, I. N. R. A., \\ Theix, 63110 Beaumont
}

\begin{abstract}
RÉSUMÉ
L'influence de la nature des protéines alimentaires sur l'aminoacidémie et l'urémie de l'Agneau préruminant est étudiée sur 5 lots d'animaux âgés de $\mathrm{I} 2$ jours environ, nourris ad libitum soit par leur mère soit par allaitement artificiel à l'aide d'aliments dont les protéines sont celles du lait de vache ou un mélange de celles du lait de vache et du lactoserum avec celles des lactoprotéines ou celles de poisson ou celles de levures d'alcanes. Les analyses sont effectuées sur le sang de la veine jugulaire. L'urémie varie dans le même sens que la teneur en matières azotées de la matière sèche ingérée. Les concentrations sanguines en la plupart des acides aminés indispensables sont d'autant plus élevées que les teneurs des aliments ingérés sont fortes. L'étude de l'urémie et de l'aminoacidémie de l'Agneau préruminant peut contribuer à en apprécier l'état nutritionnel et la qualité des protéines qu'il consomme.
\end{abstract}

Diverses études ont montré l'influence de la composition en acides aminés des protéines alimentaires sur l'aminoacidémie de différentes espèces (MuNRo, I970) et l'intérêt de ce critère pour apprécier la valeur nutritive des protéines (Pron, I973). Peu de travaux ayant été réalisés dans ce domaine chez l'Agneau préruminant (PotTter, Purser et Bergen, I972 ; Rogers et EGAN, I974), nous avons comparé l'aminoacidémie et l'urémie d'agneaux nourris par allaitement artificiel à l'aide de 4 laits reconstitués différant par la nature de leurs protéines à celles d'agneaux élevés par leur mère.

\section{MATÉRIEL, ET MÉTHODES}

$$
\text { I. - Aliments }
$$

La composition des aliments étudiés, rapportée par Theriez, Protais et Molenat (1974), figure dans le tableau I. Ce sont soit le lait maternel, soit des laits reconstitués à partir du lait de vache ou du lait de vache et du lactoserum auxquels sont associées diverses protéines représentant 
environ $50 \mathrm{p}$. Ioo des matières azotées de l'aliment : des lactoprotéines obtenues par précipitation à chaud en présence d'acide chlorhydrique des protéines de lactoserum, un concentré protéique de poisson résultat d'une hydrolyse enzymatique ménagée de poissons blancs, suivie d'une centrifugation pour éliminer une partie des lipides et des levures d'alcanes.

\section{TABLEAU I}

Composition des aliments

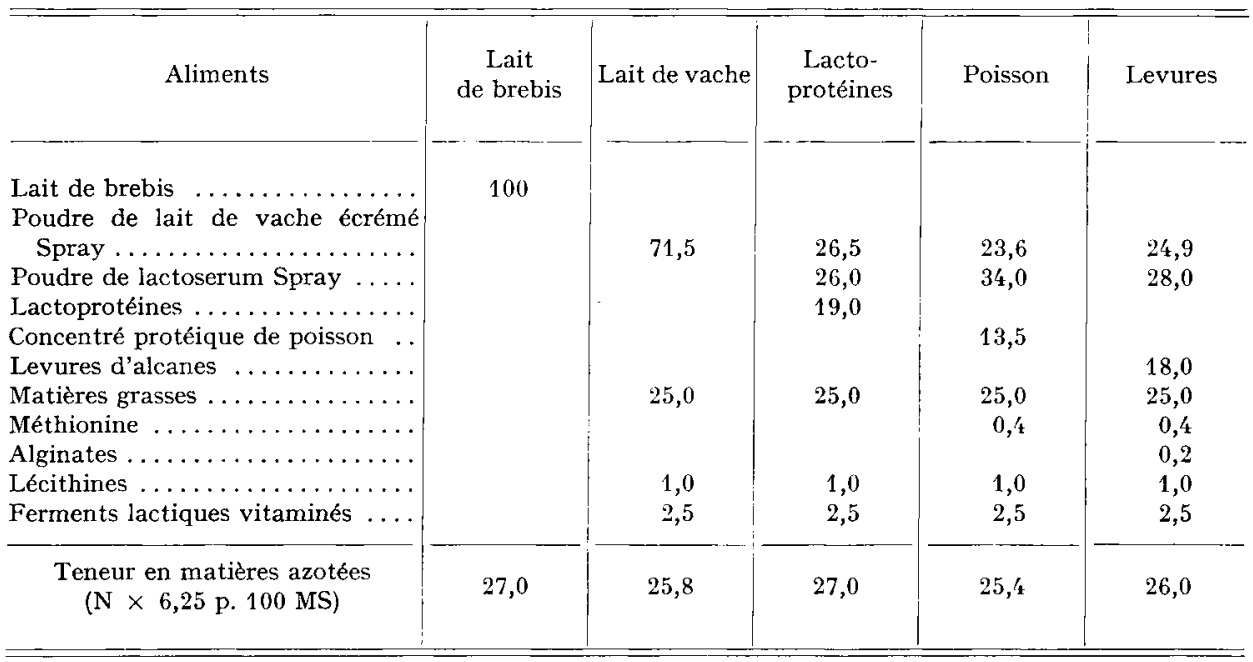

\section{2. - Animaux}

Les agneaux, Limousins ou Romanov $\times$ Limousins, sont élevés en lot en bergerie et nourris à volonté. L'influence de l'ingestion des protéines de lait de brebis sur l'aminoacidémie est étudiée sur 6 agneaux élevés par leur mère. L'étude de chacune des autres protéines est conduite sur 2 lots de 5 agneaux nourris en allaitement artificiel. Parmi ces agneaux, on en choisit 8 dont les crois-

TABLEAU 2

Performances des animaux au moment des prélèvements de sang

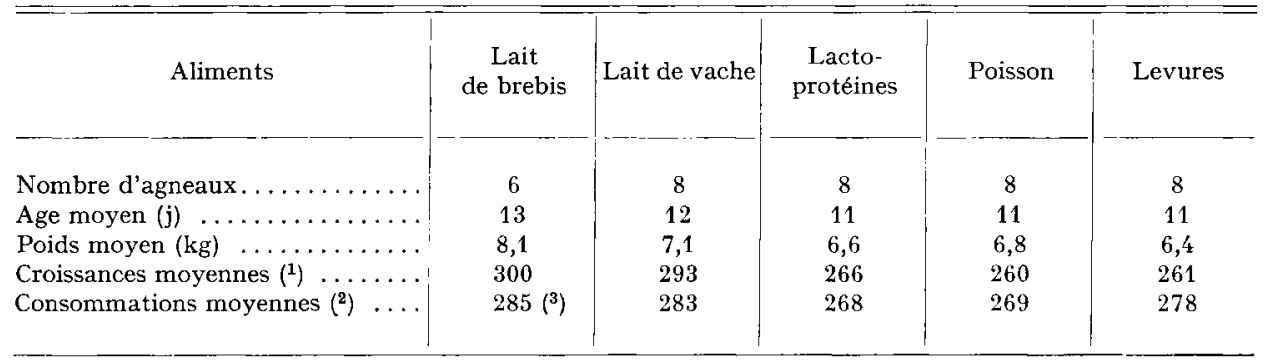

$\left.{ }^{(}\right)$Croissance moyenne $(\mathrm{g} / \mathrm{j})$ entre 3 et 18 jours pour les agneaux nourris en allaitement artificiel et entre 0 et 19 jours pour ceux élevés par leur mère.

$\left({ }^{2}\right)$ Consommation moyenne ( $g$ de matière sèche par jour) observée dans les 2 lots de 5 agneaux pendant les 2 jours précédant la prise de sang et le jour de la prise de sang.

$\left({ }^{3}\right)$ Estimée d'après l'indice de consommation observé par Theriez et al. (1973). 
sances sont satisfaisantes au moment des prélèvements pour étudier l'influence de chacune des protéines expérimentales sur l'aminoacidémie. La vitesse de croissance de chaque agneau est enregistrée, alors que seule la consommation journalière moyenne par lot peut être évaluée. Ces résultats qui permettent d'apprécier le niveau d'alimentation et l'état de santé des animaux, figurent dans le tableau 2.

\section{3. - Prélèvements et dosages}

Les prélèvements de sang jugulaire sont effectués à l'âge de $\mathrm{I} 2$ jours soit 9 jours après le début de la distribution de l'aliment expérimental pour les agneaux nourris en allaitement artificiel. Les prises de sang ont lieu entre $\mathrm{I}_{3} \mathrm{~h} 30$ et $\mathrm{I}_{4} \mathrm{~h} 3 \mathrm{O}$, c'est-à-dire 4 à 5 heures après la distribution d'aliment du matin pour les agneaux nourris en allaitement artificiel. L'urémie est mesurée dans le sang de chaque animal ; les acides aminés libres du sang sont dosés sur un échantillon moyen constitué par le mélange des fractions aliquotes de sang prélevées sur les animaux recevant le même régime. Les méthodes de dosage de l'urée et des acides aminés libres du sang ont déjà été décrites (Patureau-Mirand, Prugnaud et Pion, i973).

La composition en acides aminés des protéines du lait de brebis et de l'aliment "Lactoprotéines a été déterminée par analyse selon la méthode décrite par Pion et FauconnEAU (I966) ; celle des aliments "Lait de vache ", "Poisson " et "Levures " a été calculée à partir de la composition en acides aminés des constituants rapportée par Patureau-Mirand et al. (I974).

\section{RÉSULTATS ETT DISCUSSION}

\section{I. - Teneur en matières azotées de la matière sèche ingérée}

Une fraction des protéines des aliments " Lactoprotéines " et "Levures " tend à se déposer au fond des seaux au cours de la journée. La teneur en matières azotées et en acides aminés de la matière sèche ingérée est alors quelque peu différente de celle de l'aliment. La teneur en matières azotées de la matière sèche ingérée (tabl. 3) est estimée à partir des quantités de matière sèche distribuées et refusées, du taux protéique de l'aliment et de la teneur en azote des refus mesurée lors de l'étude de la digestibilité de ces aliments dans les mêmes conditions que celles de cette expérience. La teneur en acides aminés de la matière sèche ingérée n'a pas été mesurée. Une estimation en est faite à partir de la teneur en matières azotées de la matière sèche ingérée et de la teneur en acides aminés des matières azotées de l'aliment (tabl. 3). Cette estimation peut donc être imprécise pour les aliments "Lactoprotéines " et "Levures ". En outre, du fait de la décantation observée avec ces aliments, il n'est pas possible d'apprécier avec précision les quantités de matières azotées ou d'acides aminés ingérés pendant les heures qui suivent le repas précédant immédiatement le prélèvement de sang.

\section{2. - Teneurs en acides aminés libres}

Les teneurs en acides aminés libres sont les plus basses dans le sang des agneaux qui ingérent l'aliment "Levures " $(39,4 \mathrm{mg}$ p. Ioo g de sang) et les plus élevées dans celui des agneaux nourris au lait de brebis ou au lait de vache $(52,5$ et $54, \mathrm{I} \mathrm{mg}$ p. Ioo $\mathrm{g}$ de sang respectivement). La somme des teneurs en acides aminés libres indispensables et en tyrosine représente environ $52 \mathrm{p}$. Ioo de celle des acides aminés libres totaux dans le sang des agneaux qui reçoivent les aliments "Lait de vache ", "Lactoprotéines " et "L Levures " et $4^{8}$ p. Ioo dans celui des agneaux nourris au lait de brebis ou avec l'aliment " Poisson". 


\section{TABLEAU 3}

Composition en matières azotées

et en acides aminés indispensables de la matière sèche ingérée ( ${ }^{1}$ ) (p. 1oo) et teneurs sanguines en acides aminés indispensables libres ( ${ }^{2}$ )

(mg p. Ioo g de sang)

\begin{tabular}{|c|c|c|c|c|c|}
\hline Aliments & $\begin{array}{c}\text { Lait } \\
\text { de brebis }\end{array}$ & Lait de vache & $\begin{array}{l}\text { Lacto- } \\
\text { protéines }\end{array}$ & Poisson & Levures \\
\hline Matières azotées $(\mathrm{N} \times 6,25)$ & $27,1)$ & 26,2 & 23,6 & 95,7 & $2 / 4,5$ \\
\hline Thréonine $\ldots \ldots \ldots \ldots \ldots \ldots \ldots$ & $\begin{array}{l}1,310 \\
6,12\end{array}$ & $\begin{array}{l}1,205 \\
5,39\end{array}$ & $\begin{array}{l}1,097 \\
5,07\end{array}$ & $\begin{array}{l}1,162 \\
3,70\end{array}$ & $\begin{array}{l}1,252 \\
3,31\end{array}$ \\
\hline Valine............... & $\begin{array}{l}2,093 \\
3,80\end{array}$ & $\begin{array}{l}1,873 \\
3,74\end{array}$ & $\overline{2,50}$ & $\begin{array}{l}1,424 \\
1,97\end{array}$ & $\begin{array}{l}1,496 \\
2,03\end{array}$ \\
\hline Cystine $\ldots \ldots \ldots \ldots \ldots \ldots$ & $0,28 / 4$ & 0,235 & 0,472 & 0,245 & 0,276 \\
\hline Méthionine. & $\begin{array}{l}0,810 \\
0,8 . \bar{j}\end{array}$ & $\begin{array}{l}0,681 \\
1,12\end{array}$ & $\begin{array}{l}0,602 \\
1,08\end{array}$ & $\begin{array}{l}1,040 \\
3,93\end{array}$ & $\begin{array}{l}0,849 \\
2,78\end{array}$ \\
\hline Isoleucine $\ldots \ldots \ldots \ldots \ldots \ldots$ & $\begin{array}{l}1,539 \\
1,26\end{array}$ & $\begin{array}{l}1,506 ; \\
1,45\end{array}$ & $\begin{array}{l}1,298 \\
1,31\end{array}$ & $\begin{array}{l}1,212 \\
0,93\end{array}$ & $\begin{array}{l}1,321 \\
1,29\end{array}$ \\
\hline Leucine $\ldots \ldots \ldots \ldots$ & $\begin{array}{l}2,592 \\
2,61\end{array}$ & $\begin{array}{l}2,620 \\
2,70\end{array}$ & $\begin{array}{l}2,549 \\
2,56\end{array}$ & $\begin{array}{l}2,053 \\
1,60\end{array}$ & $\begin{array}{l}2,034 \\
1,77\end{array}$ \\
\hline $\begin{array}{l}\text { Tyr }+ \text { Phe }{ }^{(3)} \ldots \ldots \ldots \ldots \ldots \ldots \\
\text { Tyr/Phe }{ }^{(4)} \ldots \ldots \ldots \ldots \ldots \ldots\end{array}$ & $\begin{array}{l}2,754 \\
1,46\end{array}$ & $\begin{array}{l}2,738 \\
1,37\end{array}$ & $\begin{array}{l}1,970 \\
1,08\end{array}$ & $\begin{array}{l}1,882 \\
1,00\end{array}$ & $\begin{array}{l}2,174 \\
1,21\end{array}$ \\
\hline Lysine $\ldots \ldots \ldots \ldots \ldots \ldots$ & $\begin{array}{l}2,417 \\
3,02\end{array}$ & $\begin{array}{l}2,227 \\
3,94\end{array}$ & $\begin{array}{l}1,994 \\
3,89\end{array}$ & $\begin{array}{l}2,087 \\
3,97\end{array}$ & $\begin{array}{l}1,938 \\
3,06\end{array}$ \\
\hline Histidine $\ldots \ldots \ldots \ldots \ldots \ldots$ & $\begin{array}{l}0,837 \\
1,98\end{array}$ & $\begin{array}{l}0,760 \\
2,52\end{array}$ & $\begin{array}{l}0,602 \\
2,11\end{array}$ & $\begin{array}{l}0,580 \\
1,45\end{array}$ & $\begin{array}{l}0,536 \\
1,23\end{array}$ \\
\hline Arginine $\ldots \ldots \ldots \ldots \ldots \ldots$ & $\begin{array}{l}1,053 \\
2,26\end{array}$ & $\begin{array}{l}0,930 \\
2,78\end{array}$ & $\begin{array}{l}0,755 \\
2,55\end{array}$ & $\begin{array}{l}1,209 \\
3,17\end{array}$ & $\begin{array}{l}0,958 \\
2,34\end{array}$ \\
\hline Tryptophane $\ldots \ldots \ldots \ldots \ldots$ & - & 0,302 & $一$ & 0,237 & 0,265 \\
\hline
\end{tabular}

(1) Voir dans le texte: "Teneurs en matières azotées de la matière sèche ingérée ".

(2) En italique.

(3) Somme des teneurs de l'aliment en tyrosine et phénylalanine.

(4) Rapport des teneurs sanguines en tyrosine à celles en phénylalanine.

Acides aminés indispensables (tabl. 3).

Les teneurs sanguines en thréonine, valine, méthionine, isoleucine, leucine, histidine et le rapport des concentrations sanguines en acides aminés aromatiques sont les plus élevées dans le sang des agneaux qui ingèrent les aliments qui en contiennent, d'une façon générale, les plus grandes quantités ; elles sont les plus faibles, à l'exception de la thréonine, dans le sang de ceux qui ingèrent les aliments qui en contiennent le moins. Ce phénomène a déjà été observé chez les mammifères monogastriques (Rat, Porc, Homme) ou chez le Veau préruminant (LeibHolz I966, PATUREAUMrrand, Prugnaud et Pion I97I, I973). Cependant, il ne se manifeste pas dans tous les cas. Les teneurs en méthionine, isoleucine, lysine, histidine et arginine du 
sang des agneaux nourris en allaitement maternel au lait de brebis sont légèrement inférieures à celles mesurées dans le sang des agneaux qui sont alimentés en allaitement artificiel au lait de vache, bien que la composition en acides aminés des 2 laits soit très voisine. Les différences observées pourraient résulter des différences de comportement alimentaire entre les agneaux élevés par leur mère qui font de nombreux petits repas et ceux élevés en allaitement artificiel qui font un gros repas au moment de la distribution de l'aliment. Les teneurs en thréonine, lysine et arginine du sang des agneaux nourris avec l'aliment "Lactoprotéines " sont anormalement élevées compte tenu de la teneur estimée en ces composés de la matière sèche ingérée. La teneur réelle en ces acides aminés de la matière sèche ingérée dont les matières azotées peuvent être différentes de celle de l'aliment à la suite de la sédimentation d'une fraction des protéines, a pu être sous-estimée. Ces teneurs sanguines élevées peuvent aussi résulter l'utilisation imparfaite de ces acides aminés due à une déficience de l'aliment en certains acides aminés indispensables (acides aminés aromatiques) ou en un autre nutriment non déterminé. La faible teneur en thréonine libre du sang des agneaux nourris avec l'aliment "Levures " pourrait indiquer que la quantité de

\section{TABI,EAU 4}

Composition en matières azotées

et en acides aminés non indispensables de la matière sèche ingérée ( ${ }^{1}$ ) (p. roo) et teneurs sanguines en acides aminés non indispensables libres et urée ( $\left.{ }^{2}\right)$

(ing p. Ioo g de sang)

\begin{tabular}{|c|c|c|c|c|c|}
\hline Aliments & $\begin{array}{c}\text { Lait } \\
\text { de brebis }\end{array}$ & Lait de vache: & $\begin{array}{l}\text { Lacto- } \\
\text { protéines }\end{array}$ & Poisson & Levures \\
\hline A. aspartique $\ldots \ldots \ldots \ldots \ldots$ & $\begin{array}{l}2,349 \\
0,42\end{array}$ & $\begin{array}{l}2,069 \\
0,39\end{array}$ & $\begin{array}{l}2,076 \\
0,44\end{array}$ & $\begin{array}{l}2,210 \\
0,36\end{array}$ & $\begin{array}{l}2,161 \\
0,48\end{array}$ \\
\hline Sérine $\ldots \ldots \ldots \ldots \ldots \ldots \ldots$ & $\begin{array}{l}1,580 \\
2,16\end{array}$ & $\begin{array}{l}1,520 \\
2,13\end{array}$ & $\begin{array}{l}1,074 \\
2,03\end{array}$ & $\begin{array}{l}1,288 \\
1,79\end{array}$ & $\begin{array}{l}1,266 \\
1,15\end{array}$ \\
\hline Glutamine $(+$ asparagine $) \quad \ldots \ldots$ & 6,36 & 5,22 & 4,63 & 3,39 & 3,83 \\
\hline A. glutamique $\ldots \ldots \ldots \ldots \ldots$ & $\begin{array}{l}5,792 \\
1,66\end{array}$ & $\begin{array}{l}5,921 \\
1,70\end{array}$ & $\begin{array}{l}3,788 \\
1,76\end{array}$ & $\begin{array}{l}4,348 \\
1,39\end{array}$ & $\begin{array}{l}4,1^{\prime} t_{t} \\
1,70\end{array}$ \\
\hline Proline $\ldots \ldots \ldots \ldots \ldots \ldots$ & $\begin{array}{l}2,822 \\
2,98\end{array}$ & $\begin{array}{l}2,594 \\
3,66\end{array}$ & $\begin{array}{l}1,381 \\
2,67\end{array}$ & $\begin{array}{l}1,703 \\
2,66\end{array}$ & $\begin{array}{l}1,481 \\
2,36\end{array}$ \\
\hline Glycine $\ldots \ldots \ldots \ldots \ldots \ldots \ldots$ & $\begin{array}{l}0,473 \\
5,25\end{array}$ & $\begin{array}{l}0,524 \\
4,1.5\end{array}$ & $\begin{array}{l}0,425 \\
4,68\end{array}$ & $\begin{array}{l}1,274 \\
6,61\end{array}$ & $\begin{array}{l}0,798 \\
3,82\end{array}$ \\
\hline Alanine $\ldots \ldots \ldots \ldots \ldots \ldots$ & $\begin{array}{l}1,09 / \\
1,58\end{array}$ & $\begin{array}{l}0,917 \\
I, 46\end{array}$ & $\begin{array}{l}0,920 \\
1,88\end{array}$ & $\begin{array}{l}1,286 \\
1,42\end{array}$ & $\begin{array}{l}1,165 \\
1,40\end{array}$ \\
\hline Ornithine + citrulline $\ldots \ldots$ & 6,51 & 7,00 & 5,09 & 0,55 & 5,67 \\
\hline Urée $\pm s_{\bar{x}}\left(^{3}\right) \ldots \ldots \ldots \ldots \ldots$ & $38,6 \pm 2,7^{a}$ & $36,8 \pm 2,1^{a}$ & $20,4 \pm 1,1^{b}$ & $28,9 \pm 2,7$ & $22,1 \pm 2,7^{b}$ \\
\hline Matières azotées $(\mathrm{N} \times 6,25) \ldots \ldots$ & 27,0 & 26,2 & 23,6 & 25,7 & 24,5 \\
\hline
\end{tabular}

(1) Voir dans le texte : "Teneurs en matières azotées de la matière sèche ingérée. "

(2) En italique.

$\left.{ }^{3}\right)$ Les résultats affectés de la même lettre ne sont pas significativement différents $(\mathrm{P}>0,05)$. 
thréonine mise à la disposition de l'organisme est légèrement inférieure à celle qui a été estimée à cause de la décantation des protéines alimentaires ou d'une légère indisponibilité de la thréonine des levures. Toutefois cette indisponibilité de la thréonine des levures d'alcanes n'a pas été observée chez le Veau préruminant (PATurEaUMIRAND et $a l$., I974).

Acides aminés non indispensables et urémie (tabl. 4).

Les concentrations sanguines de la plupart des acides aminés non indispensables ne varient généralement pas dans le même sens que les teneurs dans le régime. Chez les agneaux nourris en allaitement artificiel, la somme des teneurs en ornithine et citrulline est d'autant plus élevée que l'urémie est forte. Celle-ci est basse dans le sang des agneaux qui consomment les aliments "Lactoprotéines ", "Levures " et "Poisson" et significativement différente de celle des agneaux nourris avec les aliments "Lait de vache " ou "Lait de brebis ". Elle varie dans le même sens que le taux protéique de la matière sèche ingérée.

Malgré la difficulté d'interprétation introduite par la sédimentation d'une fraction des protéines des aliments "Lactoprotéines " et "Levures ", il semble que, chez 1'Agneau préruminant, les concentrations sanguines en acides aminés indispensables libres dépendent étroitement de la teneur des aliments en ces composés. L'étude de l'aminoacidémie et de l'urémie de 1'Agneau préruminant devrait permettre, comme chez les autres mammifères monogastriques, d'apprécier l'état nutritionnel de l'animal et d'en déduire ses besoins en acides aminés indispensables et la qualité des protéines qu'il ingère.

Reçu pour publication en septembre 1974.

\title{
REMERCIEMENTS
}

Nous tenons à remercier M. M. C. Michel qui a bien voulu effectuer les dosages d'urée.

\author{
SUMMIRY
}

INFLUENCE OF DIETARY PROTEINS ON FREE AMINO

ACID BI,OOD LEVELS IN THE MILK-FED LAMB

This experiment was carried out to study the influence of dietary proteins on urea and free amino acids in the jugular blood of the ad libitum milk-fed lamb (aged I 2 days). The lambs of the group "Lait de brebis " were fed by suckling their dams. The lambs of the other 4 groups were reared artificially on milk replacers. Cow's milk was used as the sole source of protein in the milk replacer "Lait de vache "; in the milk replacers "Lactoproteines ", "Poisson " and "Levures", fifty per cent proteins were supplied, respectively, by a whey protein concentrate, a fish protein concentrate or alkane-grown yeast, and the other part by milk and whey (table I and THERIEZ, Protais and Molenat, I974). Urea blood levels were related to the protein content of the ingested dry matter. Essential amino acid blood levels were related to the essential amino acid content of 
the milk-replacer. Generally, the higher is the essential amino acid content in the diet, the higher is the free essential amino acid level in the blood (table 3 ). This criterion may be useful to estimate the nutritive value of dietary proteins for the milk-fed lamb.

\section{RÉFÉRENCES BIBLIOGRAPHIQUES}

Leпниогz J., I967. The source of protein in calf diets. I. A comparison of dried skim milk and meat meal. Austr. J. Agric. Res., 18, I49-I55.

Patureau-Mirand P., Prugnaud J., Pion R., i97I. Influence de la nature des protéines des aliments d'allaitement sur l'aminoacidémie libre du Veau préruminant. $X^{\mathrm{e}}$ Congr. Internat. Zootech., Versailles.

Patureau-Mirand P., Prugnaud J., Pion R., 1973. Influence de la supplémentation en acides aminés soufrés d'un aliment d'allaitement sur l'aminoacidémie. Estimation du besoin en méthionine du Veau préruminant. Ann. Biol. anim. Bioch. Biophys., 13, 225-246.

Patureau-Mirand P., Toullec R., Paruelle J. L., Prugnaud J., Pion R., I974. Influence de la nature des matières azotées des aliments d'allaitement sur l'aminoacidémie du Veau préruminant. I. Matières azotées du lait, du lactoserum, du poisson et des levures d'alcanes. Ann. Zootech., 23, 343-358.

Pion R., Fauconneau G., 1966. Les acides aminés des protéines alimentaires. Méthodes de dosage et résultats obtenus. In : A mino acides, peptides, protéines. Cahier no 6, I59-I75. A. E. C. Société de Chimie organique et biologique. Paris.

Pron R., Champredon C., Patureau-Mirand P., Prugnaud J., 1973. Quelques relations entre les acides aminés libres sanguins et musculaires et l'état de nutrition azotée des animaux. Bull. Techn. C. R. Z.V., 14, 2I-29.

Potter E. L., Purser D. B., Bergen W. G., i972. A plasma reference index for predicting limiting aminoacids of sheep and rats. J. Anim. Sci., 34, 660-67 I.

Rogers Q. R., Egan A. R., 1974. Amino acid imbalance in the suckling lamb. Fed. Proc., 33, 652 (Abstract).

Theriez M., Molenat G., Daniel M., Auroussead B., I973, L'allaitement artificiel des agneaux III. Influence de la nature des matières grasses incorporées dans l'aliment d'allaitement. Ann. Zootech., 22, I 85 -I 98 .

Theriez M., Protais M., Molenat G., I974. L'allaitement artificiel des agneaux. IV. Comparaison de différentes sources de matières azotées en remplacement de la poudre de lait. Ann. Zootech., 23, 325-34I. 